\title{
Growth Control of Cranial Base Meningiomas by Stereotactic Radiosurgery with a Gamma Knife Unit
}

\author{
Takayuki TANAKA, Tatsuya KOBAYASHI, and Yoshihisa KIDA
}

\author{
Department of Neurosurgery, Komaki City Hospital, Komaki, Aichi
}

\begin{abstract}
The effect of gamma knife radiosurgery for cranial base meningiomas was analyzed using magnetic resonance (MR) imaging in 33 patients followed up for a mean 26.5 months. There were 10 male and 23 female patients aged from 38 to 87 years (mean 54.5 yrs). Twenty-three patients had already had more than one open surgery before radiosurgery. The mean tumor volume was $16.8 \mathrm{~cm}^{3}$. The mean maximum dose was $29 \mathrm{~Gy}$ and the mean marginal dose was $15.1 \mathrm{~Gy}$. Four patients were treated by two-stage treatment at 1- to 4-month intervals. Follow-up MR imaging revealed a decrease in tumor size in 10 patients, a small low intensity area in the tumor center in three, increase in tumor size in two, and no change in 18. After radiosurgery one patient had marked edema on MR imaging and showed cognitive deficits, and another three patients had neurological deterioration. All other patients were unchanged or improved. Growth control of cranial base meningiomas without severe neurological deficits can be achieved by radiosurgery.
\end{abstract}

Key words: gamma knife, meningioma, radiosurgery, cranial base

\section{Introduction}

Meningiomas are benign tumors which constitute approximately $15-20 \%$ of intracranial neoplasms. ${ }^{12,13)}$ Complete surgical removal using microsurgical techniques is the most effective treatment, ${ }^{10,14,15)}$ but total removal of meningiomas at the cranial base is difficult without causing neurological deficits. Fractionated radiation therapy is beneficial for the treatment of partially resected meningiomas $1,3,6,7,11,17,19$ ) and recent reports have shown that stereotactic radiosurgery for meningiomas is also effective. ${ }^{4,5,8,9,16,18)}$

Here we report our results of treatment of patients with cranial base meningioma by radiosurgery using the Leksell gamma unit.

\section{Materials and Methods}

Thirty-three patients with cranial base meningiomas were treated with the gamma knife (Elekta Instruments, Stockholm, Sweden) between May 1991 and November 1992. The patients were aged from 38 to

\footnotetext{
Received February 8, 1995; Accepted May 30, 1995
}

87 years (mean 54.5 yrs). There were 23 females and 10 males. The meningiomas were located in the tentorial region in 17 cases, in the parasellar region in eight, in the olfactory groove in three, in the sphenoidal ridge in two, at the clivus in two, and in the middle cranial fossa in one case. The neurological signs and symptoms were cranial nerve pareses in 26 patients, hemiparesis in three, and cerebellar signs in two. Twenty-three patients had already had at least one craniotomy before radiosurgery. The diagnosis in the other 10 patients was based on computed tomography (CT), magnetic resonance (MR) imaging, and angiography. The mean volume of the meningiomas was $16.8 \mathrm{~cm}^{3}$ (range $0.7-33 \mathrm{~cm}^{3}$ ). Four patients with large tumors $\left(>20 \mathrm{~cm}^{3}\right)$ were treated by two-stage radiosurgery at 1 - to 4 -month intervals.

The Leksell $G$ frame was applied under local anesthesia and MR images (short repetition time) with gadolinium enhancement using 3-mm slices were taken to define the tumor margin. Dose planning was performed on a MicroVax Computer (Digital Equipment Corp., Westminster, Mass., U.S.A.). The marginal dose, usually at the $50 \%$ or greater isodose line, was selected on the basis of tumor size 
(volume) and location. Follow-up MR imaging and neurological examinations were scheduled at 3month intervals after radiosurgery.

\section{Results}

The mean maximum dose was $29 \mathrm{~Gy}$ (range 24-37.5 Gy) and the mean marginal dose was $15.1 \mathrm{~Gy}$ (10-18 Gy). The mean follow-up period was 26.5 months (range 10-34 mos).

Follow-up MR imaging revealed a decrease of tumor size (about $20 \%$ ) in 10 patients, a small low intensity area that suggested tumor center necrosis in three, an increase of tumor size in two, and no change in 18. Follow-up of neurological signs and

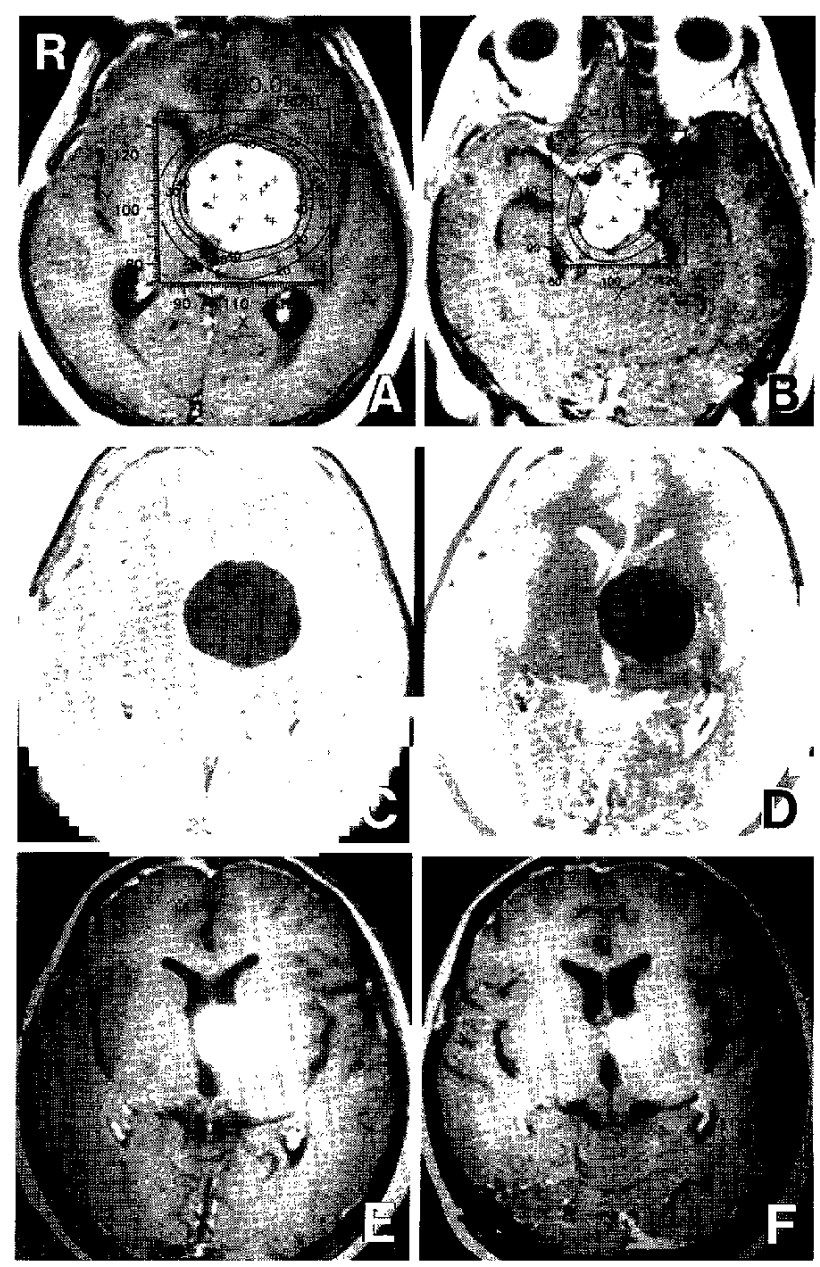

Fig. 1 Case 1. MR images showing dose planning for the upper part (A) and the lower part (B) of the tumor. Serial MR images from pretreatment (C) to $6(\mathrm{D}), 12(\mathrm{E})$, and 23 months $(\mathrm{F})$ after radiosurgery showing the tumor size gradually decreased. symptoms showed improvement in 12 patients, no change in 17, and deterioration in four.

Dose planning and post-treatment MR imaging studies for the two patients treated by two-stage radiosurgery are shown in Figs. 1 and 2.

Case 1: This 40-year-old female had already had two craniotomies before radiosurgery for malignant meningioma. The $28-\mathrm{cm}^{3}$ tumor was located in the intra- and suprasellar regions. The first radiosurgery irradiated the upper part of the tumor with a marginal dose of 12 Gy using the $40 \%$ isodose curve (Fig. 1A). The second treatment was performed 4 months later for the lower part of the tumor with the same marginal dose (Fig. 1B). Follow-up MR images 12 and 23 months after the first treatment revealed marked decrease of the tumor size (Fig. 1C-F).

Case 2: This 42-year-old female had had two

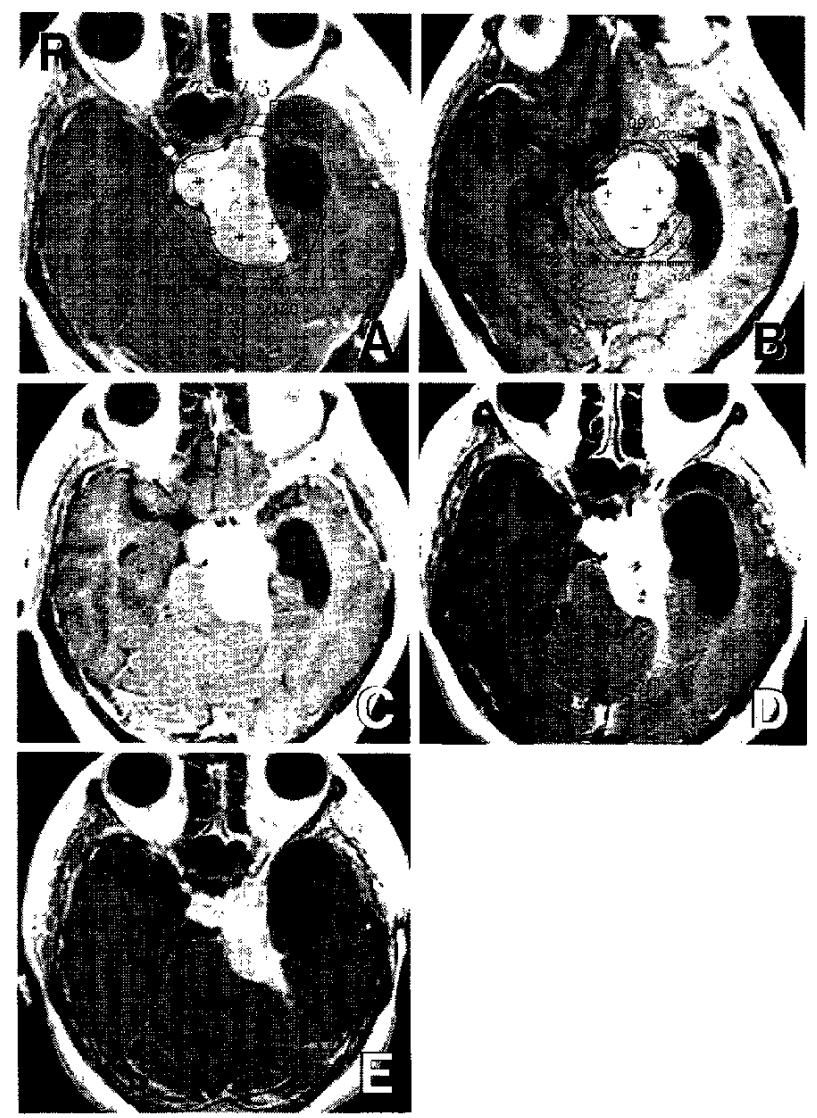

Fig. 2 Case 2. MR images showing dose planning for the first (A) and second (B) radiosurgery. Serial MR images before treatment $(C)$ and at 9 (D) and 21 months (E) after radiosurgery showing a small low intensity area in the tumor center and slight decrease of tumor size. 
craniotomies before radiosurgery for meningothelial meningioma. The $33-\mathrm{cm}^{3}$ tumor was located in the prepontine cistern and suprasellar region. The lower portion of the tumor was irradiated with a $10-\mathrm{Gy}$ marginal dose at the $45 \%$ isodose curve (Fig. 2A). The second irradiation of the upper part of the tumor 1 month later used the same marginal dose (Fig. 2B). Follow-up MR imaging showed a small low intensity area in the tumor center at 9 months and a slight decrease of the tumor size 21 months after the first treatment (Fig. 2C-E).

\section{Discussion}

Meningioma is a benign and slow growing tumor, so the goal of therapy is total surgical excision. The recent developments of neuroradiological imaging such as CT and MR imaging, and microsurgical techniques have decreased the recurrence rate of meningiomas after surgery. Mirimanoff et al. ${ }^{10)}$ reported that, following total resection, the recurrence-free rates at 5,10 , and 15 years were $93 \%, 80 \%$, and $68 \%$, respectively, at all sites. In contrast, after a subtotal resection, the progression-free rates were only $63 \%$, $45 \%$, and $9 \%$ at the same intervals. However, Bataini et al. ${ }^{2)}$ showed that meningiomas from the cranial base were associated with the highest rate of tumor recurrence, especially those growing in the clinoidal and spheno-cavernous areas. Sekhar et $a l^{151}$ found considerable progress in the surgical management of patients with intracavernous neoplasms, resulting in successful surgical removal of most cavernous sinus neoplasms. Samii et al ${ }^{14)}$ also reported that "total" removal in surgery of petroclival meningiomas was achieved in 17 patients (71\%). However, 11 patients (46\%) suffered postoperative complications, mainly in the form of cranial nerve deficits. In our series, 23 patients had been treated by craniotomy and almost all patients had developed new neurological deficits after surgery.

Conventional fractionated radiation therapy may be of value for residual meningiomas. ${ }^{1,6,7,11,17,19)}$ Taylor et al. ${ }^{17)}$ reported that the recurrence rate after subtotal resection alone was $69 \%$, which was reduced to $15 \%$ by postoperative radiation therapy using the single fraction method. Patients who received surgery alone for recurrent meningiomas achieved a local control rate of $30 \%$ after 10 years, whereas patients who received additional radiation after resection had a local control rate of $89 \% .{ }^{17}$ ) Carella et $a .^{3)}$ and others ${ }^{1,6,7,11,17,19)}$ also showed that radiation therapy by the single fraction method has an established role in the treatment of incompletely excised, recurrent, or malignant meningiomas, and in some cases, as the initial management of meningiomas.

Initial experience with stereotactic radiosurgery has recently been reported..$^{4,5,8,9,16,18)}$ Kondziolka et $a l .^{8}$ found that stereotactic radiosurgery was a relatively safe and effective therapy for selected patients with symptomatic meningiomas, including those who could not undergo surgical resection. Radiosurgery was an effective alternative primary treatment for patients whose advanced age, medical condition, or high-risk locations contraindicated surgical resection. Four of 26 patients evaluated between 6 and 12 months after treatment showed a decrease in tumor size, and 22 showed no change. Steiner $e t$ al. ${ }^{16)}$ suggested that remnants of meningioma left after microsurgery should be treated by radiosurgery. The follow-up period in our study was quite short, but MR imaging showed a decrease in tumor size in 10 patients and no change in 21 including small central necrosis areas at 10-34 months after irradiation. There was marked tumor shrinkage after the treatment in one patient (Case 1) with malignant meningioma. Coffey et al. ${ }^{4)}$ also found that radiosurgery appeared to cause dramatic early shrinkage of small and medium size intracranial hemangiopericytomas which had recurred or developed after previous surgery and/or radiation therapy.

Single-session radiosurgery might not be indicated for large volume tumors of more than $10 \mathrm{~cm}^{3}$, so we tried two-stage radiosurgery in four patients with large tumors of more than $20 \mathrm{~cm}^{3}$. They had previously had craniotomies before radiosurgery and refused further open surgery. One patient (Case 1) showed marked shrinkage in tumor size and another (Case 2) had a low intensity area in the tumor center and slight shrinkage of tumor size. Their neurological signs and symptoms were also improved. Only one of the four patients treated by two-stage radiosurgery showed marked edema around the tumor. In this patient the interval between the first and second treatments was about 2 months, suggesting that the interval in two-stage radiosurgery is important. Peritumoral edema tends to appear after about 3 months, so the second irradiation should be done at least 3 months after the first. Kondziolka et al. ${ }^{8)}$ found that three patients developed neurological deficits between 3 and 12 months after radiosurgery with the gamma knife. Engenhart et al. ${ }^{5}$ also reported late severe side effects after stereotactic radiation by a linear accelerator including five patients with a large area of brain edema, three of which were concurrent with tumor necrosis. Four of our patients had deterioration of neurological signs and symptoms, which were due to tumor growth in two 
patients and to side effects of radiation in two.

Radiosurgery can achieve growth control of cranial base meningiomas without severe neurological deficits, but extended follow-up over many years is required to evaluate the outcome for patients.

\section{Acknowledgment}

We would like to acknowledge L. Dade Lunsford, M.D., F.A.C.S. and Douglas Kondziolka, M.D., M.Sc., F.R.C.S.C. (Dept. of Neurosurgery, University of Pittsburgh, Pittsburgh, Pa., U.S.A.), for their helpful suggestions.

\section{References}

1) Barbaro NM, Gutin PH, Wilson CB, Sheline GE, Boldrey EB, Wara WM: Radiation therapy in the treatment of partially resected meningiomas. Neurosurgery 20: 525-528, 1987

2) Bataini JP, Pontvert D, Gaboriand C: Radiothérapie des méningiomes récidivants. Neurochirurgie 32: 7077, 1986

3) Carella RJ, Ransohoff J, Newall J: Role of radiation therapy in the management of meningiomas. Neurosurgery 10: 332-339, 1982

4) Coffey RJ, Cascino TL, Shaw EG: Radiosurgical treatment of recurrent hemangiopericytomas of the meninges: Preliminary results. $J$ Neurosurg 78: 903908, 1993

5) Engenhart R, Kimmig BN, Hover $\mathrm{KH}$, Wowra $\mathrm{B}$, Strum V, Kaick GV, Wannenmacher M: Stereotactic single high dose radiation therapy of benign intracranial meningiomas. Int $J$ Radiat Oncol Biol Phys 19: 1021-1026, 1990

6) Glaholm J, Bloom HJG, Crow JH: The role of radiotherapy in the management of intracranial meningiomas: The Royal Marsden Hospital experience with 186 patients. Int $J$ Radiat Oncol Biol Phys 18: 755-761, 1989

7) Goldsmith BJ, Wara WM, Wilson CB, Larson DA: Postoperative irradiation for subtotally resected meningiomas: A retrospective analysis of 140 patients treated from 1967 to $1990 . J$ Neurosurg 80: 195-201, 1994
8) Kondziolka D, Lunsford LD, Coffey RJ, Flickinger JC: Stereotactic radiosurgery of meningiomas. $J$ Neurosurg 74: 552-559, 1991

9) Lunsford LD: Contemporary management of meningiomas: Radiation therapy as an adjuvant and radiosurgery as an alternative to surgical removal? $J$ Neurosurg 80: 187-190, 1994

10) Mirimanoff RO, Dosoretz DE, Linggood RM, Ojemann RG, Martuza RL: Meningioma: Analysis of recurrence and progression following neurosurgical resection. J Neurosurg 62: 18-24, 1985

11) Petty AM, Kun LE, Meyer GA: Radiation therapy for incompletely resected meningiomas. $J$ Neurosurg 62: 502-507, 1985

12) Quest DO: Meningiomas: An update. Neurosurgery 3: 219-225, 1978

13) Russell DS, Rubinstein LJ: Pathology of Tumors of the Nervous Systems, ed 4. Baltimore, Williams \& Wilkins, 1987, pp 65-100

14) Samii $M$, Ammirati $M$, Mahran A, Bini $W$, Sepehrnia A: Surgery of petroclival meningiomas: Report of 24 cases. Neurosurgery 24: 12-17, 1989

15) Sekhar L, Sen CN, Jho HD, Jenecka IP: Surgical treatment of intracavernous neoplasms: A four-year experience. Neurosurgery 24: 18-30, 1989

16) Steiner $L$, Lindquist $C$, Steiner $M$ : Meningiomas and gamma knife radiosurgery, in Al-Mefty $\mathrm{O}(e d)$ : Meningiomas. New York, Raven Press, 1991, pp 262-272

17) Taylor BW, Marcus RB Jr, Friedman WA, Ballinger WE Jr, Million RR: The meningioma controversy: Postoperative radiation therapy. Int $J$ Radiat Oncol Biol Phys 15: 299-304, 1988

18) Valentino V, Schinaia G, Raimondi AJ: The results of radiosurgical management of 72 middle fossa meningiomas. Acta Neurochir (Wien) 122: 60-70, 1993

19) Wara WM, Sheline GE, Newman H, Townsend JJ, Boldrey EB: Radiation therapy of meningiomas. AJR 123: 453-458, 1975

Address reprint requests to: T. Tanaka, M.D., Department of Neurosurgery, Komaki City Hospital, 1-20 Jobushi, Komaki, Aichi 485, Japan. 